\title{
O LUGAR DA AFETIVIDADE NO AMBIENTE DE APRENDIZAGEM: DESAFIO DA PRÁTICA DOCENTE
}

\author{
Silvia Adriana Rodrigues ${ }^{1}$ \\ Gilza Maria Zauhy Garms ${ }^{2}$
}

RESUMO: Entre outras dificuldades, o professor passa a maior parte de seu tempo tentando criar condições para efetivar seu fazer pedagógico. A vida escolar cotidiana constitui uma realidade de cooperação e conflitos entre seus sujeitos, que pode ser menos ou mais cooperativa dependendo da forma de interagir desses sujeitos. Assim, acreditamos que uma das vias de entendimento da dinâmica escolar é esquadrinhar a qualidade das relações interpessoais entre seus atores. Nesta perspectiva, o presente trabalho verificou a representação que 50 alunos do ensino fundamental, de uma escola estadual do município de Presidente Prudente, faziam da instituição e de seus professores do ponto de vista afetivo. Nas respostas para as provocações "o que mais gosto e o que menos gosto nos meus professores" há indicativos de que a dimensão afetiva é ignorada no âmbito escolar.

\section{Introdução}

A vida cotidiana das instituições escolares constitui uma realidade de cooperação e conflitos entre os sujeitos que a compõem. E essa realidade pode ser menos ou mais cooperativa, ou conflituosa, dependendo da forma de interagir desses sujeitos. Entretanto, a interação social depende da maneira como as pessoas se percebem, uma vez que a percepção que temos de outrem é influência de nossas experiências passadas, preconceitos e valores, que interferem de forma definitiva nas relações humanas, como também de nosso estado emocional momentâneo. Em outros termos, uma das vias de entendimento dos conflitos no interior da escola é acerca da qualidade das relações interpessoais entre seus atores.

\begin{abstract}
A relação afetiva vai buscar as suas componentes menos no domínio intelectual do que ao domínio da subjetividade. É verdadeiramente no plano da sensibilidade que se deve procurar a natureza profunda das relações professor-aluno, mais do que no plano da atividade intelectual (Mauco, 1968, p. 145).
\end{abstract}

Leite (1991) aponta que os alunos não se percebem pelos olhos do professor, e que este processo talvez não fosse tão nocivo, se os professores conseguissem adotar posturas imparciais diante de situações que geram simpatia ou antipatia. Esta não é uma tarefa simples, e quase todos os professores se deixam levar, muitas vezes inconscientemente, por favoritismos ou indiferença, sem perceber as marcas que estas atitudes cunham nos alunos, uma vez que tanto a simpatia quanto à antipatia se configuram em formas de interação.

\footnotetext{
${ }^{1}$ Mestranda em Educação da FCT/UNESP de Presidente Prudente; Professora Substituta do Departamento de Educação da UFMS - Campus de Três Lagoas. onlysil@uol.com.br

${ }^{2}$ Professora Doutora do Departamento de Educação e da Pós Graduação em Educação da FCT/UNESP de Presidente Prudente gmzauhy@ hotmail.com
} 
Nesta perspectiva, o presente trabalho foi desenvolvido objetivando verificar a representação que alunos de duas salas de $5^{\text {a }}$ série do ensino fundamental fazem da escola e de seus professores a partir do ponto de vista afetivo. A coleta dos dados foi realizada numa uma escola estadual do município de Presidente Prudente, com 50 alunos, dos períodos diurno e noturno.

\section{Afetividade e educação: entrecruzando os caminhos}

A escola, e conseqüentemente os indivíduos que a compõem, percebem seus atores como indivíduos apartados de uma experiência "extra-escolar", como se os contextos casa e escola, apesar de se constituírem duas realidades diferentes, não abarcassem os mesmos sujeitos, que necessitam destas e de outras realidades, distintas e complementares, para se constituírem como ser único. Ou seja, os atores educacionais, professores, alunos, etc., não são considerados a partir da condição humana de totalidade e singularidade. Estes são vistos destituídos de características como emoção e afeto, atribuindo-lhes apenas as características necessárias ao ambiente escolar, como por exemplo, a cognição.

Para Galvão (1993), as condutas individuais resultam do conjunto formado pelas situações vivenciadas pelos sujeitos, e assim sendo, o entendimento destas condutas deve ser buscado nas relações estabelecidas entre o sujeito e no meio em que elas se manifestam e na interação deste sujeito com outros meios nos quais se insere.

Segundo Almeida, (1999, p. 107):

[...] as relações afetivas são, em alguns grupos, predominantemente o motivo das suas agregações, fato que não ocorre com a escola, na qual a razão primeira de sua existência está na responsabilidade com o conhecimento. Entretanto, mesmo na escola, as relações afetivas se evidenciam, pois a transmissão do conhecimento implica, necessariamente, uma interação entre pessoas.

Para Almeida (1993, p. 41):

[...] o que parece-nos essencial na relação ensinar-aprender é que se reconheça a afetividade do aluno como uma dimensão inseparável, indissociável da inteligência, promotora de desenvolvimento, e que o educador tenha, ele mesmo, clareza de sua própria afetividade enquanto educador, considerado na função de professor ou de pai, ou seja, na condição de educador, em seu estatuto de adulto.

Na contramão desta necessidade, nas últimas décadas, a escola tem ficado à margem dos estudos acerca do desenvolvimento afetivo da criança posto que tem sido a atividade intelectual, o foco dos estudos das pesquisas acadêmicas. Almeida (1997), em artigo que é substrato de sua dissertação de mestrado, dá atualidade a denúncia de Ribot, realizada em 1896, para o fato de que a produção científica deixou de lado o papel que as emoções e as paixões desempenham na vida humana.

Segundo Leite (1991, p. 234): "[...] nem a Sociologia, nem a Psicologia e nem a Filosofia da Educação têm considerado o domínio das relações interpessoais como um problema central." O mesmo autor denuncia que: "[...] como problema científico, o tema das relações interpessoais é muito recente no pensamento sistematizado, embora algumas das 
relações interpessoais - como o amor, o ódio e a amizade - sejam aspectos fundamentais da vida humana".

No entanto, o estudo sobre a combinação harmoniosa das dimensões afetivas e cognitivas do pensamento não é algo atual, e Piaget (1954, apud Lajonquiere, 1993, p. 128) mesmo não considerando a possibilidade de a afetividade modificar as estruturas da inteligência, não nega a importância de se pensar a questão:

Em um primeiro sentido, pode-se dizer que a afetividade intervém nas operações da inteligência; que ela estimula ou perturba; que ela é causa de acelerações ou de atrasos no desenvolvimento intelectual; mas que ela não será capaz de modificar as estruturas da inteligência como tal [...] Em um segundo sentido, pode-se dizer, ao contrário, que a afetividade intervém nas estruturas da inteligência; que ela é a fonte de conhecimentos e de operações cognitivas originais. Numerosos autores têm sustentado este ponto de vista.

Um dos autores que sustentam o segundo ponto de vista é Henry Wallon, que, já em 1925, dedicava-se ao seu estudo do fenômeno emoção. A rigor, sua obra ressalta a unicidade psicobiológica do ser humano, o qual defende uma análise genética das relações entre os aspectos biológico e social na formação da personalidade do indivíduo.

Wallon, numa visão de conjunto, tematizou a questão das emoções numa teoria que não privilegia a emoção em detrimento da cognição, ao contrário, chama a atenção para a relação complementar entre afetividade e inteligência. Considerando desse modo, que a evolução integral do ser humano depende, sobremaneira, da reciprocidade entre ambas. Traz uma nova forma de conceber a motricidade, a emotividade, a inteligência e a gênese humana, realizando, a partir desta concepção, estudos centrados na criança contextualizada, onde concebe o ritmo no qual se sucedem as etapas do desenvolvimento de forma descontínua, marcado por rupturas, retrocessos e reviravoltas, provocando em cada etapa profundas mudanças nas anteriores.

Nesse sentido, a passagem dos estágios de desenvolvimento não se dá linearmente, por ampliação, mas por reformulação, instalando-se, no momento da passagem de uma etapa a outra, crises que afetam a conduta da criança. Conflitos se instalam nesse processo e são de origem exógena quando resultantes dos desencontros entre as ações da criança e o ambiente exterior, estruturado pelos adultos e pela cultura e endógenos e quando gerados pelos efeitos da maturação nervosa. (Galvão, 1995). Esses conflitos constituem-se em propulsores do desenvolvimento.

Para o autor, afetividade e inteligência evoluem ao longo do desenvolvimento, estas são construídas e se modificam à medida que o indivíduo se desenvolve. Nesse movimento as necessidades afetivas vão se tornando cognitivas, sendo possível considerar uma unicidade psicobiológica, onde os aspectos afetivos e cognitivos se alternam em termos de predominância dependendo da atividade. Contudo, cabe ressaltar que não se trata da exclusão de um aspecto em função do outro, mas de um jogo de alternâncias em que um se oculta para que o outro possa emergir. Conclui-se então, que se há oposição entre o aspecto afetivo e o cognitivo, há também complementaridade.

O antagonismo entre afetividade e inteligência ocorre exatamente pela impossibilidade de parceria, no momento de uma crise emocional. O poder subjetivo das emoções (que volta a atividade do sujeito para suas disposições intimas, orgânicas), incompatibiliza-se com a necessária objetividade das operações intelectuais. Analogamente, é 
possível constatar que a atividade intelectual voltada para a compreensão das causas da emoção reduz seus efeitos, uma crise emocional tende a se dissipar mediante atividade reflexiva. A rigor, a relação entre a emoção e razão é de filiação, e, ao mesmo tempo, de oposição.

Desta forma, a teoria walloniana nos revela que é na ação sobre o meio humano, e não sobre o meio físico, que deve ser buscado o significado das emoções. Sendo então, a escola um espaço onde as emoções estão presentes, e o professor tem um papel essencial no desenvolvimento afetivo da criança. A partir da convicção de que educar é desenvolver a inteligência conjuntamente com a emoção, a escola não pode ignorar a vida afetiva de seus alunos.

\section{O bom professor na visão dos alunos}

Conforme apontado anteriormente o objetivo deste trabalho foi o de verificar, a partir da visão dos alunos, como são definidos os bons professores. Desta forma, temos um trabalho de cunho qualitativo, de caráter exploratório, que dada a especificidade do objeto utilizou a adoção de alguns pressupostos necessários para o estudo de caso. Para tanto, foi aplicado um questionário aberto, onde os alunos foram solicitados a apontar o que mais gostavam e o que menos gostavam nos professores. A justificativa para escolha desta abordagem é a de verificar se a necessária unicidade psicobiológica defendida por Wallon se apresenta dicotomizada ou não na realidade escolar cotidiana.

Os termos mais frequientes usados pelos alunos para qualificar o que mais gostam em seus professores oferecem um primeiro esclarecimento. Se comparados aos termos mais utilizados para explicar "o que menos gosto nos meus professores", temos uma visão de conjunto dos fatores aparentes que determinam as relações positivas no aluno, como pode ser observado no quadro comparativo das justificativas apontadas pelos alunos.

\begin{tabular}{|c|c|}
\hline \multirow{2}{*}{$\begin{array}{l}\mathrm{O} \text { que mais } \text { gosto é quando meus } \\
\text { professores... }\end{array}$} & $\mathrm{O}$ que menos gosto é quando meus \\
\hline & professores.. \\
\hline $\begin{array}{l}\text { - Explicam de uma maneira fácil e com } \\
\text { calma a matéria. }\end{array}$ & - Não ensinam, não explicam. \\
\hline - São alegres. & - São injustos. \\
\hline - Ensinam descontraídos e felizes. & - Ficam bravos e gritam. \\
\hline - Dão mais atenção, nos atendem. & - Brigam por injusta causa. \\
\hline - Respeitam e ajudam. & - São quietos e nervosos. \\
\hline - Explicam individualmente. & - Não dão atenção aos alunos. \\
\hline - Quando estão de bom humor. & - Quando estão irritados e de mau humor \\
\hline - Gostam de dar aula. & - São autoritários. \\
\hline - São compreensivos. & $\begin{array}{l}\text { - Chamam a nossa atenção na frente dos } \\
\text { outros. }\end{array}$ \\
\hline - Elogiam. & - Não sabem explicar a matéria. \\
\hline - Não faltam às aulas. & - Faltam às aulas. \\
\hline - $\quad$ Promovem diálogo. & - $\quad$ Desrespeitam os alunos. \\
\hline - Brincam com os alunos. & - Brigam e discutem com os alunos. \\
\hline - Dão uma boa aula. & - Dão aulas cansativas e monótonas \\
\hline - $\quad$ Estão com vontade de dar aula. & - Não querem nada com nada \\
\hline
\end{tabular}


A qualidade do professor que aparece como essencial é o respeito pelos alunos (45,9\%). Isto é, como afirma Mauco (1968), a sua disponibilidade afetiva positiva, disponibilidade esta traduzida em ações como compromisso com o ensino e a aprendizagem dos alunos. É o interesse do professor pelos alunos e pelo trabalho que aparece como aspecto fundamental para o estabelecimento de uma boa relação, como pode ser observado nas falas dos alunos:

O que mais gosto é quando meus professores explicam bem a matéria; estão alegres; ensinam descontraídos e felizes; nos respeitam; dão atenção; são liberais; dão aulas; nos ensinam; explicam individualmente; me dão atenção; mudam aquele método antigo de ensinar e fazem a aula ficar descontraída; me ajudam; quando estão de bom humor; variam as atividades; são compreensivos; me elogiam; me atendem; não faltam às aulas; dialogam; dão aulas interessantes; estão com vontade de dar aulas.(Aluno $C$ )

A contraprova desta constatação manifesta-se nas justificativas do questionamento para o "que menos gosto em meus professores", em que o não compromisso com o ensino e a aprendizagem, traduzidos pelo desinteresse do professor pelos alunos aparece como um fator fundamental percepção negativo para com os professores. Os alunos, na multiplicidade de razões que recorrem para justificar a contrariedade, são quase unânimes em descrevê-los como "chatos", "mal-humorados", "irritados", "nervosos", "bravos", "gritam", "autoritários", "faltam às aulas", "injustos".

A última vez que me senti muito aborrecido foi quando pedi explicação a um professor e ele com estupidez disse que não iria explicar mais; quando vêm irritados e mal-humorados; me culpam por injustiça; ficam bravos; são nervosos; começam a gritar como loucos; não ensinam; não explicam; falta de paciência; não me dão atenção; estão com problemas e descontam na gente; me chamam a atenção na frente dos outros;quando faltam às aulas; nos desrespeitam; são autoritários;não querem nada com nada; não sabem explicar bem. (Aluno F)

É, portanto o desdenhar expresso e a agressividade do professor que determinam a relação conflituosa. É que muitas vezes, como afirma Mauco (1968, p.136) “... o professor reage como se a criança fosse um adulto e sente pessoalmente como uma agressão às reações inadaptadas do aluno".

São sem dúvida os sentimentos positivos do professor (interesse, compreensão, respeito, alegria, bom humor, atenção, gostar de ensinar, paciência, etc.) que sentidos pelos alunos, promovem em grande parte os seus sentimentos de simpatia. Em contrapartida, o professor irritado, mal-humorado, autoritário, nervoso, não gosta de ensinar, sem paciência, injusto, faltam às aulas, etc., provoca sentimentos negativos, como a antipatia.

As "falas" dos alunos parecem indicar a presença de um clima de antagonismo entre o aspecto afetivo e o aspecto cognitivo dos sujeitos envolvidos na relação pedagógica. Segundo Wallon, este antagonismo ocorre exatamente pela impossibilidade de parceria, no momento de uma crise emocional, momento em que o "circuito perverso" pode instalar-se. Ou seja, os indivíduos não conseguem reagir de forma corticalizada frente a reações emocionais alheias.

No caso a postura de agir corticalmente caberia ao professor, que teoricamente encontra-se mais estruturado em termos cognitivos. O perigo de se estabelecer o 
"circuito perverso" é o fato de que, uma vez instaurado, o sujeito fica completamente alheio à realidade circundante.

O poder subjetivo das emoções incompatibiliza-se com a necessária objetividade das operações intelectuais. É como se a emoção embaçasse a percepção do real, impregnando-lhe de subjetividade e, portanto dificultando reações intelectuais coerentes e bem adaptadas.De maneira análoga, é possível constatar que a atividade intelectual dirigida para a compreensão das causas de uma emoção minimiza seus efeitos, uma crise emocional tende a se diluir por meio de uma atividade reflexiva.

As reflexões feitas até o momento parecem indicar que se realmente existe uma unicidade psicobiológica, ou seja, que a associação entre os aspectos afetivos e cognitivos, como também a predominância de um dos aspectos citados, dependendo da atividade.

\section{Considerações finais}

Wallon acreditava numa educação direcionada para a construção da personalidade integral do sujeito, destacando a importância de não dicotomizar a inteligência da afetividade, alertando sobre os riscos de uma educação onde a afetividade é subestimada. Além disso, deixou claro que o país fascista onde a inteligência foi ignorada e o instinto exacerbado mostrou a quais aberrações selvagens se pode chegar. Para evitar a volta à barbárie, é crucial educar a sensibilidade conjuntamente com a razão. Assim sendo, a escola não pode negligenciar ou até suprimir o espaço da emoção em suas atividades. (Dantas, 1990)

A escola e, principalmente, o adulto precisa conhecer o modo de funcionamento da emoção para aprender a lidar adequadamente com suas expressões.O professor deve ter clareza sobre o que é emoção, como funciona, para poder administrá-la em si e no outro. É um grande desafio, uma vez que os progressos da inteligência que são responsabilidade do professor dependem, em grande parte, do desenvolvimento da afetividade.

Cabe salientar que este é ainda é um estudo preliminar sobre o assunto, a primeira proposta de outros projetos já em andamento. Mas, as representações dos alunos obtidas a partir das respostas sobre as provocações "o que mais gosto e o que menos gosto nos meus professores", apontam para o desafio citado acima, pois são indicativos de que a dimensão afetiva está sendo ignorada no âmbito escolar.

Nesse sentido, a escola, enquanto espaço legítimo para a educação dos sujeitos, precisaria articular a união da vida afetiva com a vida intelectual para, concomitantemente, nos limites das suas atividades educacionais, promover $o$ desenvolvimento de ambas.

Por considerar a relação afetiva o foco das percepções sentidas pelos sujeitos investigados como fator que pode, e deve, estar interferindo no processo ensinoaprendizagem, afirma-se:

A relação afetiva vai buscar as suas componentes menos no domínio intelectual do que ao domínio da subjetividade. É verdadeiramente no plano da sensibilidade que se deve procurar a natureza profunda das relações 
professor-aluno, mais do que no plano da atividade intelectual (Mauco, 1968, p. 145).

Garantir a transmissão do conhecimento é fundamental, mas, devemos também nos preocupar com uma outra dimensão que é o lado emocional do ser humano. Ter claro qual o papel na escola na vida e para a vida aparecem nas falas quando os alunos buscam respostas sobre qual(is) expectativa(s) têm sobre a escola e o que de mais importante ela tem para lhe oferecer:

Ótimo ensino; oportunidade de ser alguém na vida; ensino de boa qualidade; estudos; futuro melhor; toda a vontade de me ensinar a crescer; educação e um bom aprendizado; aprender; conhecimento; ser uma boa pessoa; educação e respeito; ensinar melhor; colocar professores competentes; conhecimento e amor. (Aluno H)

Integrar os aspectos cognitivos e afetivos no processo de desenvolvimento do potencial dos indivíduos é essencial para a formação integral das pessoas. No entanto, é a estrutura emocional que dá suporte ao desenvolvimento intelectual. Assim sendo, podemos afirmar que o aspecto afetivo tem profunda influência sobre o desenvolvimento intelectual. Ele pode acelerar ou diminuir o ritmo do desenvolvimento. Dessa maneira, o desenvolvimento intelectual apresenta dois componentes: um cognitivo e outro afetivo.

A afetividade, nesta perspectiva, segundo Dantas (1992):

[...] não é apenas uma das dimensões da pessoa; ela é também uma fase do desenvolvimento, a mais arcaica. O ser humano foi, logo que saiu da vida puramente orgânica, um ser afetivo. Da afetividade, diferenciou-se, lentamente, a vida racional. Portanto, no inicio da vida, afetividade e inteligência estão sincreticamente misturadas, com o predomínio da primeira. A sua diferenciação logo se inicia, mas a reciprocidade entre os dois desenvolvimentos se mantém de tal forma que as aquisições de cada uma repercutem sobre a outra permanentemente. (p.90)

Considerando este caminhar, o processo da construção da pessoa será organizado por uma sucessão de momentos dominantemente afetivos ou dominantemente cognitivos, não paralelos, mas integrados. Isto significa que a afetividade depende, para evoluir, de conquistas realizadas no plano da inteligência, e vice-versa.

As reflexões permitiram inferir que - apesar de muitas pessoas ainda acreditarem que o raciocínio é mais adequado quando desvinculado da emoção e que emoções dificultam pensar objetivamente - o raciocínio desprovido de sentimento, torna o processo decisório satisfatório praticamente impossível, a questão não é excluir o sentimento do processo de tomada de decisão diário, mas sim balanceá-lo, encontrando a dose apropriada de emoção e sua correta expressão.

A rigor, o grande desafio é manter o equilíbrio entre a razão e a emoção, isto porque a emoção traz consigo a tendência de reduzir a eficácia do funcionamento cognitivo e neste sentido ela é regressiva. Contudo, a qualidade do comportamento ficará na dependência da capacidade cortical em retomar o controle da situação. Se assim ocorrer, embora seja a afetividade um componente permanente da ação, ela se reduzirá. 
Em sentido geral, como afirma Dantas (1992) é possível descrever a emoção como potencialmente anárquica e explosiva, imprevisível, e por isso assustadora. Está aí a razão pela qual é tão raramente enfrentada pela reflexão pedagógica.

$\mathrm{Na}$ interação entre adultos e crianças, cuja temperatura é mais elevada, os resultados do "circuito perverso" são sentidos frequentemente. Tão raramente tematizada, esta questão passa assim para o primeiro plano, o que significa que a educação da emoção dever ser incluída entre os propósitos da ação pedagógica, o que supõe o conhecimento interior do seu modo de funcionamento.

Observa-se, portanto, que a teoria walloniana aplicada à educação é relevante e constitui-se como rico material de amparo para análise do processo ensinoaprendizagem em todos os níveis. Este referencial fornece pistas importantes para o crescimento pessoal e profissional dos docentes. Galvão (1995) ao apontar as contribuições da teoria de Wallon à educação coloca que a abrangência do objeto de estudo da psicologia genética do autor, se utilizada como instrumento a serviço da reflexão pedagógica, sugere que a educação deve ter por meta não somente o desenvolvimento intelectual, mas a pessoa como um todo e ao destacar o papel do meio social no desenvolvimento infantil, concebe a escola como meio promotor do desenvolvimento.

O enfoque walloniano sobre o meio escolar oferece subsídios para a compreensão das condutas individuais, mas também para a organização do trabalho com a classe. [...] convida o professor a organizar a classe em coletivo, desenvolvendo o espírito de cooperação [...] adverte que não basta defender o trabalho em equipe, já que este pode estimular a rivalidade e a competição - o trabalho em equipe deve ser, portanto, orientado para a solidariedade entre seus membros.

[...] O professor é valorizado do ponto de vista do conteúdo. Não se deve colocar como exclusivo detentor do saber e único responsável pela sua transmissão, mas tampouco abdicar deste papel, submetendo-se indiscriminadamente à espontaneidade infantil. Para Wallon, respeitar a criança não significa poupá-la das intervenções externas [...] ao contrário, a intervenção do professor é fundamental para o processo de desenvolvimento e aprendizagem, que depende da incorporação do patrimônio cultural adulto, isto é, de conteúdo. (Galvão, 1993 p. 38)

É essencial que os professores percebam a importância que têm e assumam suas responsabilidades, para que cheguem a conclusão de que não são meros fornecedores de meios para a aprendizagem e sim pessoas que fazem um intercâmbio entre emoções e cognição e que viabilizam momentos de trocas de experiências emocionais.

\section{Referências Bibliográficas}

Almeida, A. R. S. (1997). A emoção e o professor: um estudo à luz da teoria de Henri Wallon.En Psicologia: Teoria e Pesquisa. Brasília, vol. 13, n. 2, 239-249. 
Almeida, S. F. C. de. (1993). O lugar da afetividade e do desejo na relação ensinar-aprender. En Temas de Psicologia. n. 1, 31-44.

Dantas, H. (1992). A afetividade e a construção do sujeito na psicogenética de Wallon. En La Taille, Y de; Oliveria, M. K. de; Dantas, H. Piaget, Vygoysky, Wallon: teorias em discussão (pp. 85-100). São Paulo: Summus.

Galvão, I. (1996). Henry Wallon. Uma concepção dialética do desenvolvimento infantil. 3 ed. Petrópolis: Vozes.

(1993). Uma reflexão sobre o pensamento pedagógico de Henri Wallon. En DURAN, M. C. G. (coord.). Construtivismo em Revista. (pp. 33-39). São Paulo: FDE Diretoria Técnica (Série Idéias, n. 20).

Lajonquiere, L. (1992). Do sujeito epistêmico a um sujeito (do desejo). En . $D e$ Piaget a Freud: para repensar as aprendizagens (pp. 128-139) $3^{\mathrm{a}}$. ed. Rio de Janeiro: Vozes, p. 128-139

Leite, D. M. (1991). Educação e relações interpessoais. En Patto, M. H. S. (org.). Introdução à psicologia escolar (pp. 235-357). 3ª . ed. São Paulo: T. A. Queiroz.

Mauco, G. (1968). Psicanálise e escola. En . Psicanálise e Educação (pp. 114-169) Lisboa: Mores Editora Ltda.

Wallon, H. (1971). As origens do caráter na criança: os prelúdios do sentimento de personalidade. São Paulo: Difusão Européia do Livro. . (1975). Psicologia e educação da infância. Paris, Lisboa: Editorial Estampa. . (1995). A evolução psicológica da criança. $2^{\mathrm{a}}$. ed. Lisboa: Edições 70. 